Revista de Estudios Histórico-Jurídicos

[Sección historia del derecho público]

XLIII (Valparaíso, Chile, 2021)

[pp. 165-185]

\title{
El OfiCiO Y LA “JUBILACiÓN”. CATEgorías Y LENGUAjE EN UNA CULTURA JURISDICCIONAL
}

[Office and "retirement". Categories and language in a jurisdictional culture]

\author{
Javier BARRIENTOS GRANDON* \\ Universidad Autónoma de Madrid, España**
}

\begin{abstract}
RESUMEN
La concepción del oficio con jurisdicción, enraizada en la categoría de deber, condujo en la cultura del derecho común a que se entendiera como una cierta carga (onus), que el oficial cumplía mediante su u s o y e je r c i c i o. A éste se hallaba obligado, en principio, de por vida, y sólo podía liberarse de él por un acto del príncipe, cuyo contenido era la e x o n e r a c i ó n. Ésta, en un primer momento, asumía el exclusivo carácter de merced, esto es, de un acto que retribuía los méritos y servicios del oficial, mediante la liberación de su uso y ejercicio, y la conservación de su salario y honores, y al que acostumbró denominarse con la expresión "retirarse a gozar del salario en su casa”. En el siglo XVII esa terminología fue desplazada por
\end{abstract}

\begin{abstract}
The concept of office with jurisdiction, grounded on the ought category, led in the common law culture, to understand it as a certain burden (onus) born by the one holding the office in the act of using and exercising it. Officers were, in principle, committed for a lifetime and only a Sovereign Act could release them from service by way of an exoneration. Exonerations at first were exclusively merciful, that is, acts rewarding the merits of the officers and their service, by way of releasing the use and exercise of the office, and they could maintain their salary and honors, which was usually referred to as "retiring home to enjoy your salary". In the $17^{\text {th }}$ century, this phraseology was replaced by the term "retirement". This concept reached its full
\end{abstract}

* Académico de número de la Academia Chilena de la Historia, profesor de Historia del Derecho y de las Instituciones en la Facultad de Derecho de la Universidad Autónoma de Madrid. Dirección postal: C/ Kelsen No 1, Ciudad Universitaria de Cantoblanco, $28049 \mathrm{Ma}-$ drid - EsPaña. Dirección electrónica: javier.barrientos@uam.es ORCID 0000-0002-7353-2054

** Abreviaturas: Aca. = Archivo de la Corona de Aragón (Barcelona). Agi. = Archivo General de Indias (Sevilla). Ags. = Archivo General de Simancas (Simancas). Ahn. = Archivo Histórico Nacional (Madrid). ARGN. = Archivo del Reino y General de Navarra (Pamplona). 
la voz j u b i 1 a c i ó n . Ésta se consolidó bajo dos especies: una que asumía la tradición de la merced real, y otra que revestía el carácter de decisión dirigida a apartar del ejercicio al oficial, por justas razones.

$$
\begin{gathered}
\text { Palabras clave } \\
\text { Oficio - Uso y ejercicio - jubilación }
\end{gathered}
$$

meaning under a two-fold approach: one assuming the tradition of the royal mercy and the other one, featured by being a decision aimed at removing the officer from exercise on fair grounds.

\section{KeY Words}

Office - Use and Exercise - Retirement

RECIBIDO el 30 de abril de 2021 y ACEPTADO el 8 de junio de 2021

\section{INTRODUCCIÓN}

La consolidación del oficio con jurisdicción en la cultura del derecho común, sobre la base de una concepción cultural que lo reconducía la noción de deber, se proyectó en todos los aspectos de su disciplina.

El uso y ejercicio del oficio se concebía como el cumplimiento de los deberes impuestos por el oficio y, en cuanto que los oficios jurisdiccionales eran, en principio, perpetuos, como los servidos por letrados en consejos y audiencias, el oficial resultaba obligado de por vida a usar de él y a ejercerlo.

La exoneración de esa obligación sólo podía tener su origen en el príncipe, que era quien había creado y provisto el oficio. Uno de los supuestos de exoneración fue el de la jubilación.

En este breve artículo se ofrecerá una descripción del curso que siguió el supuesto que dio pie a que se configurara la categoría de la jubilación durante los siglos XVI y XVII. Fue este un proceso en el que, además, de dotarla de un cierto contenido, dio lugar a unas voces y términos peculiares, tanto entre los juristas como en la práctica de las secretarías, y a ellas se le prestará especial atención.

\section{OFICIO Y CARGA (ONUS)}

En la cultura del derecho común, la gestación y definición del oficio público y de sus perfiles se situó en el espacio de la teología cristiana. Ligado en ésta a la construcción de su radical concepción antropológica, apoyada en la tradición de una filosofía cristiana marcada por el peso de Aristóteles y singularmente de la segunda stoa, halló en Tomás de Aquino a su más influyente expositor. De ese campo propio extendió su influjo al del derecho, y lo hizo desde los tempranos tiempos de los comentaristas medioevales, y a partir del siglo XVI en adelante fue también notorio su peso en los escritores políticos, ocupados en obras de gobierno de príncipes y repúblicas ${ }^{1}$.

En esa antropología cristiana lo más propio del hombre era, en palabras de

\footnotetext{
${ }^{1}$ Vid. Barrientos Grandon, Javier, La Cámara de Castilla: 'Méritos', 'servicios'y 'suficiencia en la provisión de oficios del Consejo de Indias en tiempos de Felipe II (1588-1598), en Boletín de la Academia Chilena de la Historia, 126 (2017), pp. 157-160.
} 
Tomás de Aquino, “entender y obrar a impulsos de la razón”. En cuanto que por ésta podía proponerse sus propios fines, se podía predicar su libertad, pero, como también podía ser dominado por otro, era posible que se hallara en esclavitud: la del pecado si se miraba a la materia espiritual o la civil si se atendía a la temporal. Esta dicotomía, libertad-esclavitud, era la que daba origen al estado de los hombres, porque éste se refería a la obligación de su misma persona, en cuanto que ella podía "ser dueña de sí misma o depender de otra, y no por causa leve o fácilmente mutable, sino por algo permanente, que es lo que implica el concepto de libertad o esclavitud"2. Esta visión cristiana del estado resultaba fácilmente acomodable a la que los juristas, a la luz de los textos del Corpus Iuris Civilis, concebían y desarrollaban en las variadas distinciones de una pluralidad de estados que era, a su vez, causa de la pluralidad de personas, justificadas ambas por una razón de perfección del orden natural.

Si la libertad o esclavitud causaba, radicalmente, la pluralidad de estados y personas, era la pluralidad de los actos humanos la que lo hacía respecto de la pluralidad de oficios. Era aquí un texto de Isidoro de Sevilla el que, con una discutible etimología, había permitido al de Aquino relacionar las acciones y el oficio: "En sus Etymologías dice, que oficio se deriva del verbo 'efficere', y se dice 'officium' en vez de 'efficium' por eufonía, y puesto que el obrar (efficere) se refiere a la acción, los oficios se distinguen por sus actos"’3. Así resultaba que, además de la distinción de estados, otra se tomaba "respecto de la acción, y es la distinción de oficios, pues se dice que están en oficios distintos aquellos que están dedicados a diversas acciones" ". Por eso los oficios se distinguían propiamente según los actos que se referían a otros, al igual que se decía, por ejemplo, que el médico o el juez, tenían un oficio ${ }^{5}$.

Esta concepción del oficio irrigó a la cultura europea en sus más variadas manifestaciones. Uno de sus reflejos más significativos fue el de su paso al lenguaje común. Muestra de ello, por ejemplo, la ofrecía en 1611 el Tesoro de la lengua castellana o española de Sebastián de Covarrubias, que se limitaba a recoger esa significación común de la voz oficio: "V ulgarmente significa la ocupación que cada uno tiene en su estado, y por esso solemos decir del ocioso y desacreditado, que ni tiene oficio, ni beneficio" ". De ahí también que al acabar el siglo XVIII Juan José Sánchez pudiera destacar esa pluralidad de oficios, junto a la diversidad de sus campos operativos, cuando escribía que: "La inteligencia de dicha voz Oficio se encontrará que la tiene sobre toda acción y operación justa del hombre; por cuya generalidad es verdadero decir, que abraza indistintamente qualquiera ocupación lícita de las muchisimas que hay establecidas en la República". Así, continuaba, si se quería saber el ejercicio de cualquier sujeto: "Si

\footnotetext{
${ }^{2}$ Summa Theologiae, II'-IIae, q. 183, art. 1.

${ }^{3}$ Ibíd., art. 3.

${ }^{4}$ Ibíd.

${ }^{5}$ Ibíd.

${ }^{6}$ Covarrubias y Orozco, Sebastián de, Tesoro de la lengua castellana o española (Madrid, por Luis Sánchez, 1611), fol. 567v.

${ }^{7}$ SÁncheZ, Juan Josef, Nobleza, privilegios y prerrogativas del oficio público de escribano (Valencia, Imprenta de los Hermanos de Orga, 1797), II, Parte I, cap. V, n. 2, fol. 8.
} 
es el de Juez, se ha de decir que tiene Oficio de tal, y si el de sastre, que lo usa de este destino; de forma, que añadiendo a la voz general Oficio el genitivo específico de cada ocupación, se sabrá quantas se contienen en lo bumano".

El oficio y sus distinciones pendían radicalmente de las acciones humanas, de ahí que, en definitiva, su contenido se ligara necesariamente a la propia concepción del acto humano. Si en cuanto a ella la antropología cristiana bebió de fuentes aristotélicas, pesó más la tradición estoica transmitida por Cicerón. Zenón de Citio había acuñado la noción de kathekon, entendida como acción conveniente a la naturaleza, y Cicerón, en un célebre pasaje de una de sus cartas a Ático, no había dudado en traducirla por la latina officium que, aplicada a las acciones humanas, en cuanto que procedían de una naturaleza racional, se volvía en acto conforme a esa naturaleza y, por ello, en acto debido moralmente, porque esa naturaleza racional, en cierto modo, obligaba a esa acción y no a otras ${ }^{9}$. Así, junto a la errada, pero decisiva culturalmente, etimología isidoriana, se alzaba otra, que la hacía derivar de opus facio, en tanto que obra o acción que debía realizarse.

Esa tradición estoica del oficio no halló dificultad para convivir con la de matriz isidoriana y, más aún, fue asumida sin dificultades por la teología cristiana. En esta línea, el oficio no era más que una cierta acción debida, en cuanto que acto conforme a la naturaleza racional del hombre, y por ello su estudio y disciplina se insertaban en el campo de la teología moral y, a través de ella, se proyectaba en todos los espacios de la cultura. El peso de esta concepción se hizo sentir en el lenguaje común, que tempranamente se hizo cargo de ella, como lo registraba Nebrija en los primeros años del siglo XVI. En su Dictionarium había escrito que al oficio se lo tomaba "por la obra del hombre en quanto hombre", porque "oficio se dice, generalmente, de toda acción honesta conveniente a cada uno"11. En esa misma línea se situaba la primera acepción que el Diccionario, llamado de autoridades, daba al oficio en 1737: "La obra que cada uno debe hacer, y en que está ocupado, según el lugar y estado que tiene" 12 .

La variedad de actos humanos causaba la pluralidad de los oficios. Esa misma diversidad daba lugar a que en la sociedad se presentaran multitud de ellos, y que con esto la propia voz oficio acabara por admitir su uso en distintos modos. Tal era, al promediar el siglo XVI, la advertencia de Scot en su muy influyente Vocabularium: "Se dice oficio de muchos modos"13, pero en todos ellos había una nota que los reconducía a su radical naturaleza de "acción debida"14.

En su más temprano uso, la voz officium se había asentado en el espacio de los

${ }^{8}$ Ibíd.

${ }^{9}$ Cicero, M. Tullius, De finibus bonorum et malorum libri $V$ (Lipsiae, sumptibus Augusti Lehnhold, Lipsiae, 1831), XVIII, 58, fol. 234

${ }^{10}$ Nebrija, Antonio de, Dictionarium latinohispanicum, et viceversa bispanicolatinum (Antuerpia, in Aedibus Ioannis Steelsii, 1560), sin foliar. Voz 'officium'.

${ }^{11}$ Ibíd.

${ }^{12}$ Diccionario de la lengua castellana, en que se explica el verdadero sentido de las voces (Madrid, Imprenta de la Real Academia Española, por los Herederos de Francisco del Hierro, 1737), V, fol. 21.

${ }^{13}$ ScOт, Alexander, Vocabularium iuris utriusque (Lugduni, apud Symphorianum Beraudum, 1572), fol. 477: "Officium dicitur multis modis".

${ }^{14}$ Barrientos Grandon, Javier, El oficio y su proyección en el lenguaje de las residencias: 'bueno, recto 
actos humanos referidos a las virtudes o hábitos y, por ende, en una esfera que tocaba a sus actos privados, principalmente a los debidos por amicitia, amor, pietas, etc. De ahí, que no extrañe que a principios del siglo XVI Covarrubias registrara en su Tesoro la palabra oficioso como la de quien era: "amigo de dar a todos contento"15. Así, uno de los modos en que se usaba de la voz oficio era el peculiar al espacio de lo doméstico, en el que, por ejemplo, era habitual hablar del oficio de padre o madre. También se hallaba extendido a otros ámbitos ligados a la gestión de las cosas privadas (res privata), como el de las artes y ocupaciones mecánicas, o el comercio, de guisa que era común el uso de expresiones singulares, como oficio de sastre, oficio de maestro, oficio de mercaderes, o genéricas como oficios mecánicos. En el lenguaje del derecho, igualmente, se hallaba recibido algún uso en este modo y este espacio, como en las querellas de testamento inoficioso o de inoficiosa donación, rescindibles por contrarias al officium pietatis, o en el agente oficioso que, sin mandato y sólo por oficio de amistad, asumía la gestión de los negocios de alguien ausente o impedido.

A Cicerón se debió la extensión del uso de la palabra oficio al campo de lo público (res publica). En aquel ya mencionado pasaje de una de sus cartas a Ático, y para oponerse a la visión que éste tenía del oficio ceñido a lo privado, había escrito que: "Para mí no hay duda que el kathékon de los griegos es nuestro officium. Ahora, por qué dudas de que iba a entrar incluso en el lenguaje de la cosa pública (res publica) ¿acaso no decimos oficio de los cónsules, oficio del senado, oficio de los generales"16. Este texto contribuyó a sentar en la cultura europea la singularidad de los oficios públicos, y no halló dificultad para insertarse en el contexto de la genérica concepción cristiana del oficio. Así, tampoco obstó a que fuera asumido y desarrollado por los juristas, que contribuyeron a vestir al oficio en su campo propio con las ropas de los textos del Corpus Iuris Civilis, ocupados en glosar y comentar sobre todo aquellos títulos del Digesto, en los que se trataba del oficio de diversos magistrados $(1,10-22)$ y, muy particularmente, de su título De iurisdictione $(2,1)$.

La noción de oficio público se delineó como comprensiva de las acciones debidas por aquellos que gestionaban los negocios públicos (res publica) y en relación con éstos, sin que admitiera en este ámbito, como desde el siglo XVI se destacaba en el conocidísimo Lexicon juridicum, su uso respecto de las cosas privadas, y por ello se aplicaba a los magistrados, pues estos se habían introducido por razón de pública utilidad y no privada ${ }^{17}$.

y limpio juez', en Andújar Castillo, F. y Ponce Leiva, P. (coord.), Debates sobre la corrupción en el Mundo Ibérico, siglos XV T-XVII (Alicante, Biblioteca Virtual Miguel de Cervantes, 2018), pp. 84-87

${ }^{15}$ Covarrubias y Orozco, Sebastián de, cit. (n. 6), fol. 567v.

${ }^{16}$ Cicero, M. Tullius, Epistolae ad Atticum (Ingolstadii, ex Typographia Adami Sartorii, 1615), lib. XVI, 14, n. 3, fol. 568: “Mibi non este dubium quin quod Graeci kathékon, nos 'officium'. Id autem quid dubitas quin etiam in rem publicam praeclare caderet? Nonne dicimus 'consulum officium, senatus officium, imperatoris officium?"

${ }^{17}$ Prateius, Pardulfus, Lexicon juris Civilis et Canonici, sive potius Thesaurus, de verborum, quae ad Ius pertinent, significatione, P. Prateio ex variis Collectore (Lugduni, apud Guliel. Rovillium, 1567), fol. 142r: "In privatum usum non cadit, uti est magistratus, \& id genus aliae functiones: verum etiam quod propter publicam utilitatem est introductum". 
Del modo en que la voz oficio se decía de las acciones convenientes y debidas por alguien, se pasó en el lenguaje, por singular metonimia, al modo en que se la empleaba para llamar a aquel que debía esas acciones. Este fenómeno se produjo no sólo respecto de los oficios privados, sino también de los públicos. En cuanto a éstos, comenzaron, entonces, a convivir esos dos modos: el uno, para designar a las acciones debidas por aquel a quien se había confiado la gestión de intereses públicos, y el otro, como se explicaba en el ya citado Lexicon juridicum, para decir "oficio por la persona del juez o del magistrado, esto es, por aquel que cumple el oficio"18. Este último modo estaba íntimamente ligado a otro, que también se registraba en el referido Lexicon, decir "oficio por los ministros, magistrados y gobernadores (praesides)"19.

En ese curso semántico se afincó en la cultura del derecho común el modo que concebía al oficio público como significativo de la realidad incorporal que comprendía la variedad de acciones debidas por aquel a quien se confiaba la gestión de intereses públicos. En este uso officium se conectaba con la voz onus, pues su contenido de acciones debidas se presentaba como peso y carga. De ahí que, por nuevo tropos, en este modo oficio se dijera por cargo. Agudamente lo advertía Covarrubias en su Tesoro: “Cargo, vale algunas veces peso, y por alusión los oficios y gobiernos se llaman cargos por la carga y cuydado que traen consigo, y en la lengua Latina se juega del vocablo al sonido. 'Honos y onus'"20.

En el caso de los oficios con jurisdicción, creados y provistos por el rey, la carga (onus) que les daba consistencia, era la propia carga que Dios había impuesto al rey, porque él mismo era concebido como un oficio (officium principis, officium regis), cuya causa era Dios. Éste le había puesto en el reino, como a su cabeza, para que persiguiera el fin de mantenerlo en justicia en el orden temporal, en cuanto que le había atribuido la jurisdicción. Era esta una visión tempranamente asumida en la cultura europea, de la que en los reinos de España daban buena muestra diferentes textos legales, como en Navarra el prefacio de las Ordenanzas dadas por Carlos III en Olite el 1 de junio de 1413 y, tiempo antes, en Castilla las Siete Partidas. En estas, en una de sus leyes $(2,1,5)$ se leía que: "Vicarios de Dios son los Reyes, cada uno en su Reyno, puestos sobre las gentes, para mantenerlas en justicia, e en verdad quanto en lo temporal, bien assi como el Emperador en su Imperio". El fin para el cual estaba puesto por Dios se le volvía carga: la de hacer justicia en su reino: "E los santos dixeron, que el Rey es puesto en la tierra en lugar de Dios, para cumplir la justicia, e dar a cada uno su derecho". Era, precisamente, esta carga con la que había de "cumplir" la que dotaba de especialidad a sus acciones, en cuanto que príncipe, y la que daba consistencia a su oficio porque, como sentenciosamente apuntaba Quevedo en su Política de Dios y gobierno de Christo: "Cumplir el Rey toda justicia, es bacer todo su oficio" 21 .

$\mathrm{El}$ "oficio del Rey no es tanto de operación exterior [...] quanto de aprehensión interior,

\footnotetext{
${ }^{18}$ Ibíd.: "Officium pro persona iudicis vel magistratus".

${ }^{19}$ Ibid., fol. 142v: "Officium pro ministris magistratuum, ac praesidum".

${ }^{20}$ Covarrubias y Orozco, Sebastián de, cit. (n. 6), fol. 202 r.

${ }^{21}$ Quevedo y Villegas, Francisco de, Politica de Dios i Govierno de Christo; sacada de la Sagrada Escritura para acierto del Rey $i$ Reyno en sus acciones (Madrid, a expensas de Pedro Coello, 1655), Parte II, cap. XIX, fol. 264.
} 
la qual de su naturaleza puede abrazar infinitas cosas, no como infinitas, sino como aquellas que se pueden reduæir a pocos puntos", según advertía Juan de Santa María ${ }^{22}$. De ello concluía que a estos puntos: "Debe siempre entender el sabio y prudente Rey, y hacer por si las que puede, y le tocan de oficio, y las otras por sus ministros" ${ }^{23}$. Desde esta perspectiva, su oficio se explicaba con imagen cardinal: "Como el coraçon en el cuerpo, que por sí solo no puede hacer todos los oficios, que particularmente hazen todos los miembros, pero mediante diversos instrumentos, miembros, y órganos, embiando a ellos su virtud, se balla en las operaciones de todos. El Rey es el coraçon del Reyno, y ha de obrar como él, no haziéndolo todo por sí solo"24. El príncipe, así, podía obrar "baziendo el oficio de Rey por su persona”, en palabras de Jerónimo Zurita en su Historia del Rey Don Hernando, ${ }^{25}$ o "por sus ministros" en las de Santa María, porque ministros era otra voz ya asentada en el siglo XVI para decir oficio. Covarrubias la explicaba al comenzar aquella centuria como la del "que ministra y sirve a otro", porque "ministerio" no era sino "el oficio que a cada uno incumbe ministrar"26.

Hacía, pues, el rey su oficio al crearlos en su reino, pues por este medio se descargaba de sus acciones debidas para conservarlo en justicia. Al ejercitar la jurisdicción, que le había sido atribuida para el cumplimiento de sus fines, con el acto consistente en la institución de oficios, obraba como su causa, fuente y origen, y les comunicaba algún grado de su propia jurisdicción. Con la provisión en un oficio público, el príncipe satisfacía aquello que debía, pues implicaba hacer su oficio y descargar su conciencia. Con ella, en verdad, cargaba al provisto con unas acciones que, en su origen, eran propias del oficio del príncipe, de guisa que cuando el proveído usaba de su oficio no sólo hacía el suyo propio sino también el del rey. No era simple figura la cláusula que, en relación con ciertos oficios, se incluía en el despacho de su nombramiento para advertir al provisto que debía liberar su conciencia y la del príncipe. Así, era uso y estilo que en el papel de provisión de la presidencia o gobierno del Consejo Real se incluyera esta frase: "Espero que cumplireis de manera con las obligaciones del oficio, y que descargueis mi conciencia y la vuestra"27.

El provisto en un oficio, cumplía con la carga que él le imponía, mediante su "uso y ejercicio". Eran estas, dos palabras habitualmente mancornadas en el lenguaje del oficio público, pero también lo estaban en el habla común. Ellas daban cuenta de la estrecha ligazón que había entre el príncipe y quienes servían los oficios públicos, pues de ellos había fiado, en buena parte, el cumplimiento

${ }^{22}$ Santa María, Juan de, Tratado de republica y policia cbristiana. Para reyes y principes: y para los que en el gobierno tienen sus vezes (Barcelona, por Sebastian de Cormellas, 1618), fol. 20.

${ }^{23}$ Ibíd.

${ }^{24}$ Ibíd.

${ }^{25}$ Zurita, Jerónimo, Historia del Rey don Hernando el Catholico. De las empresas, y ligas de Italia (Zaragoza, por Lorenzo de Robles, 1610), V, libro I, fol. 15v.

${ }^{26}$ Covarrubias y Orozco, Sebastián de, cit. (n. 6), fol. 550r.

${ }^{27}$ En AhN. Consejos, Leg. 51.433, n. 1, "Nombramientos y posesiones de SS Presidentes, Governadores i Ministros del Consejo, entierros", por ejemplo, podía leerse en el que se dirigió el 15 de diciembre de 1692 a don Manuel Arias: "Por la satisfaccion que tengo de buestra persona, y celo con que me servis os be nombrado para el Gobierno del Consejo y asi tomareis la Posesion el Miercoles y espero que cumplireis de manera con las obligaciones del oficio, que descargueis mi conciencia y la buestra". 
de su propio officium principis, que, según se ha visto, consistía en la realización de los actos humanos para que se cumpliera la justicia en su reino, que era el cargo que Dios le había puesto al confiarle la jurisdicción.

$\mathrm{El}$ " "uso", no era más que: "El acto y exercicio de usar alguna cosa", como explicaba Covarrubias $^{28}$, y "exercicio" era: "El acto de exercitarse en alguna cosa"29. Si estas breves definiciones no hacían más que confirmar la relación que había entre ambos términos, era su explicación de la voz "exercer" la que daba la clave cultural para entenderlas. De esta apuntaba: "Exercer, es lo mesmo que exercitar, o usar, como exercer uno el oficio de escrivano" 30 , y agregaba que: "Es tanto como servirle, y administrarle por su persona" 31 .

Así uso y ejercicio se revelaban como términos que, por una parte, se asumían como de contenidos equivalentes y, por otra, que referidos a un oficio público implicaban necesariamente su servicio por la propia persona, y no por medio de otra, pues era opinión común que, salvo expreso privilegio, el oficio real no podía servirse por teniente o substituto, a diferencia de los oficios canónicos, en que la substitución era ordinariamente admitida ${ }^{32}$. Este servicio personal era consecuencia de que la provisión en el oficio tenía por una de sus causas a la confianza que el príncipe hacía del provisto. Ella era, como queda dicho, razón esencial para que el príncipe, al conceder el oficio, fiara del provisto el descargo de su conciencia. "Usary ejercer" un oficio, eran "servirle", pero no de cualquier modo, sino personalmente. Aparecía el servicio como el término que conectaba al uso y ejercicio con el oficio. El servicio, lo decía también Covarrubias era: "La obra que se haze sirviendo" 33 , que servir no era otra cosa que: "Obedecer a otro, y hazer su voluntad"34.

El uso y ejercicio del oficio público imponían al provisto en él la realización de todos los actos que condujeran al desempeño del cargo en el que consistía el mismo oficio. No en vano servir el oficio era llamado, entre otras voces, con la de "desempeñar", porque el oficio público "empeñaba" al provisto, esto es, lo obligaba como si hubiera dado "peños" o prendas, y su ejercicio lo "desempeñaba", a él y al príncipe. Que "desempeñar", como lo recogía el Diccionario de autoridades en una

\footnotetext{
${ }^{28}$ Covarrubias y Orozco, Sebastián de, cit. (n. 6), fol. 61r [2 $2^{a}$ foliación].

${ }^{29}$ Ibíd., fol. 392r.

${ }^{30}$ Ibíd.

${ }^{31}$ Ibíd.

${ }^{32}$ Rocco, Francisco, De officiis, eorumque regimine opus decisionibus supremorum magistratuum illustratum (Neapoli, ex Regia Typographia Aegidii Longhi, 1669), rubrica IV, De substitutione in Officiis, n. 1-2, fol. 21: "Quod Jure Canonico permittitur, ut quilibet ordinarius potest sibi constituere Vicarium [...] Jure Civili tamen vetitur, substituere aliquem in officio, l. 1, ff. de offic. ejus [Dig. 1, 21, 1], auth. Ut nulli judicum in princ. [Nov. $134=$ Auth. 9, 9, pr.] \& in auth. de collat $\int$ ad haec probibemus [Nov. 128, c. $20=$ Auth. 9, 11, 20], l. nullus, qui nexu, C. de decur. [Cod. 10, 32, 60] ubi hoc dicitur in summa, non potest quis servire per substitutum, nisi babeat de boc privilegium, aut vero illustris persona sit'.

${ }^{33}$ Covarrubias y Orozco, Sebastián de, cit. (n. 6), fol. 27r [2 foliación].

${ }^{34}$ Ibíd.
} 
de sus acepciones, era: "Cumplir alguno aquello a que es obligado, por su punto y honra"35, porque: "Desempeño, vale también cumplimiento de la obligación"36.

El oficio se mostraba, entonces, como un medio para que, a través de él, obrara la voluntad del príncipe que, en este punto, no podía verse más que como la de cumplir con los deberes que le eran propios, esto es, la de que el provisto en él asumiera una carga del príncipe, y con su uso y ejercicio se desempeñara y lo descargara de ella.

\section{LA “EXONERACIÓN" DEL OFICIO: “GRATA LICENCIA" Y "SALARIO EN SU CASA"}

Los oficios con jurisdicción provistos por el príncipe eran, en principio, perpetuos, lo que implicaba que el provisto en ellos estaba obligado, de por vida, a su "uso y ejercicio", lo que no era más que decir que pesaba sobre él su carga (onus) hasta el fin de sus días. Precisamente se consolidó como de estilo una cláusula en los títulos que se despachaban a los provistos, con unos términos como estos: "Es ntra merced y tenemos por bien que por el tiempo que nuestra voluntad fuere seais del nuestro consejo" ${ }^{37}$. Tales provisiones, a voluntad del príncipe, se entendía por los juristas que eran perpetuas, pues, como afirmaba Cenedo, fundado en la doctrina de Baldo, el oficio a beneplácito del príncipe, y el oficial designado a su beneplácito, se estimaba perpetuo ${ }^{38}$.

En cuanto que el uso y ejercicio, como carga (onus) en la que consistía el oficio con jurisdicción, procedía del príncipe, sólo éste podía liberar de ella al oficial. A este acto de liberación, en general, se acostumbró llamarle "exoneración", pues, como ya podía leerse en el famoso Diccionario de Calepino, exonerar, no era más que libertar de una carga ${ }^{39}$. La vía para obtenerla era solicitar la "licencia" del príncipe, para dejar la carga del oficio, que ya en una de sus acepciones, según lo recordaba Covarrubias: "Algunas vezes licencia significa libertad"40.

La causa más general, para que el oficial solicitara la exoneración del uso y ejercicio de su oficio, era la concurrencia de circunstancias que le impidieran continuar su desempeño, es decir, que obstaban a que pudiera perseverar en el cumplimiento de los deberes que el oficio le imponía. Las más frecuentes de tales circunstancias eran la crecida edad del oficial, sus achaques, o alguna dolencia, que le dificultaba o tornaba inhábil para el recto uso y ejercicio, como la ceguera

${ }^{35}$ Diccionario de la lengua castellana, en que se explica el verdadero sentido de las voces (Madrid, Imprenta de la Real Academia Española, por la viuda de Francisco del Hierro, 1732), III, fol. 156.

${ }^{36}$ Ibíd.

${ }^{37}$ Ahn. Consejos, libro 726, fol. 244r, título de consejero de Castilla expedido a favor de don Francisco de Valcárcel, Madrid, 29-XI-1634.

${ }^{38}$ Cenedo, Pedro, Practicae quaestiones canonicae, et civiles, tam utriusque iuris, quam sacrarum Literarum studiosis utilissimae (Zaragoza, apud Ioannem a Lanaja \& Quartanet, 1614), quaest. XVIII, n. 22, fol. 169: "Iuxta doctrinam Bald. in d. l. Iurisperitos ff de excus. tut. ubi ait officium ad beneplacitum Principis, \& officialem ad eius beneplacitum assignatum, esse perpetuum".

${ }^{39}$ Calepino, Ambrogio, Dictionarium linguae latinae (Basileae, ex officina Hieronymi Curionis, 1566), sin foliar, "Onero": "Exonero [...] quod est onus detrabo".

${ }^{40}$ Covarrubias y Orozco, Sebastián de, cit. (n. 6), fol. 524r. 
o sordera. Así, por ejemplo, podía apreciarse en el real decreto fechado en Zaragoza el 18 de abril de 1644, por el que se exoneraba al marqués de Loriana de la presidencia del Consejo de Hacienda: "He nombrado a Don Francisco Antonio de Alarcon por Presidente de mi cons ${ }^{\circ}$ de hazienda por haver suplicado el marques de Loriana le hiziese mrd de exonerarle de aquella ocupacion por su edad y falta de salud y haviendo venido yo en ello y nombrado al marques por mi consejero de estado he hecho esta mrd de la Presidencia de barienda a Don Fran." Antonio" ${ }^{\text {"41 }}$.

A la edad y achaques, como causa de la exoneración, se unía también una razón de mérito, pues, el oficial auxiliaba su súplica de exoneración en los servicios y méritos contraídos, precisamente, en el uso y ejercicio de los oficios que habían estado a su cargo durante su vida. Desde esta perspectiva, el acto de la exoneración asumía el carácter de merced, es decir, de justa retribución. Así, cuando el príncipe exoneraba a un oficial del uso y ejercicio, la liberación de esa carga, le hacía una merced y, en cuanto que tal, su contenido lo fijaba el propio príncipe. Tal contenido, además del cardinal, consistente en la liberación del uso y ejercicio, se enteraba con el goce del salario, o de una parte de él, y la conservación de los honores y preeminencias del oficio del que se le exoneraba. Como ejemplar de lo que queda dicho, puede leerse el decreto de exoneración de don Miguel de Salamanca, del gobierno del Consejo de Hacienda, fechado en Madrid el 24 de febrero de 1666: "Por las repetidas instancias que me ha hecho Don Miguel de Salamanca Governador del Consexo de hazienda para dexar este puesto; he venido en exonerarle del, por su maior consuelo conservandole en todo los honores prerrogativas, preheminencias grado y lugar que con el dicho Gobierno tiene en los concursos y Juntas, con los demas Presidentes, como si actualmente le sirviera sin diferencia alguna; y continuandosele el quento de mrs que oi goza en la parte que le tiene" ${ }^{\text {"42. }}$.

En el contexto de esa comprensión cultural, la práctica de la exoneración del uso y ejercicio del oficio en la Monarquía hispánica, generó un lenguaje propio, que ya se mostraba como consolidado durante el siglo XVI y, aunque fue variable en el tiempo, perduró con matices y con mayor o menor fuerza en ciertos ámbitos, hasta el propio momento en que los oficios públicos se desvanecieron en una nueva cultura.

En cuanto que la exoneración implicaba el cese de la carga de concurrir al consejo o tribunal, en el cual el oficial debía desempeñar su oficio, en el siglo XVI se consolidó en el uso de las secretarías el recurso a la expresión "retirarse a su casa”, para significar, precisamente, la liberación del uso y ejercicio. Como ella, además, era consecuencia de la licencia concedida por el príncipe, satisfecho de los méritos y servicios contraídos, por el oficial, solía unirse a la voz "licencia” o a la más expresiva locución "grata licencia".

Así, por ejemplo, cuando la Cámara de Castilla consultaba el 11 de septiembre de 1597 una plaza de alcalde de hijosdalgo de la Audiencia y Chancillería Real de Valladolid, advertía que ella estaba vacante por "baberse de retirar a su casa con grata licencia de V. M.” el licenciado Carrillo de Morales ${ }^{43}$. Este mismo uso se apreciaba

\footnotetext{
${ }^{41}$ Aнn. Estado, leg. 6.401-1, n. 13.

${ }^{42}$ Ibíd., n. 19.

${ }^{43}$ Ahn. Consejos, leg. 13.529, n. 13.
} 
en el despacho de los títulos de los oficios, como podía leerse en el de oidor de la Contaduría Mayor de Hacienda, expedido al licenciado Francisco Manso en Aranjuez el 8 de abril de 1614, en lugar del licenciado "Gabriel de Viñaspre que con nuestra grata licencia se [b] a retirado a su casa" ${ }^{4}$.

La "grata licencia", además del "retiro a su casa", iba acompañada del goce del salario o de una parte de él, concedido como particular merced, en cuanto que retribuía los servicios realizados y los méritos contraídos por el oficial. Buen ejemplo de esta concepción cultural podía verse en la real cédula que, fechada en Madrid el 23 de julio de 1624, se dirigió a la Audiencia de los Grados de Sevilla, para mandarle que se pagara el salario al licenciado Álvaro Méndez de Parada, pues en ella se recordaba que: "Por otra [cédula] de veintidós de abril deste año, teniendo consideración a lo mucho que nos havía servido y a que se hallaba muy viejo le concedimos licencia para retirarse a su casa, escusandole de la ocupación de la plaza con retención del salario y emolumentos que con ella tenía de la manera y en el mismo lugar y antigüedad con que la gozava" ". Por esta misma época, y con expresa referencia a la exoneración y a su cara de merced, podía leerse el título de gobernador, capital general y presidente de la Real Audiencia del reino de Chile, que se despachó en Madrid el 23 de febrero de 1611 a don Alonso de Ribera: "Por quanto, teniendo consideración a lo mucho y bien que me ha servido Alonso García Ramón, mi gobernador y capitán general que al presente es de las provincias de Chille y presidente de mi Audiencia Real dellas, y a su mucha edady enfermedades, he tenido por bien de exonerarle de aquellos cargos y que goce del salario en su casa y de proveer en su lugar a vos Alonso de Ribera [...]"46.

La exoneración del uso y ejercicio del oficio, significada con la expresión "retirarse a su casa", y la merced unida a ella de "gozar del salario" ya liberado de los deberes del oficio, dio pie a que a una y a otra se las llamara con una sola expresión, desde la perspectiva del oficial: "gozar del salario en su casa" y, desde la perspectiva del acto del príncipe: "darle el salario en su casa". Estas expresiones, y otras equivalentes, ya se hallaban en uso en las primeras décadas del siglo XVI, y fueron muy frecuentes en tiempos de Felipe II. Con ellas, entonces, se designaba a una muy específica merced real, hecha a quien había servido un oficio. Consistía ella en que, por los méritos contraídos en el servicio del oficio, unidos, o a la vejez, achaques o enfermedades, que le impedían o estorbaban continuarlo debidamente, se le permitiera que, sin servirlo, pudiera retirarse a su casa con el goce entero de su salario. Así, con esta merced, por una parte, se exoneraba al oficial del servicio del oficio y, por otra, se procuraba asegurarle que pudiera sustentarse en su casa, esto es, que no se viera precisado a servir o a darse a otras ocupaciones lucrativas, para que pudiera gozar del descanso.

Hacia 1523 se leía en el Informe que, dirigido al emperador y atribuido a Lorenzo Galíndez de Carvajal, daba cuenta de quienes formaban el Consejo Real y de las partes que cada uno tenía. Al tratar de las cosas que convenía proveer, para que la Audiencia y Chancillería Real de Granada estuviera en orden, se proponía

${ }^{44}$ Ahn. Consejos, libro 724, fol. 172 r.

${ }^{45}$ Ahn. Consejos, libro 726, fol. 231v-233r.

${ }^{46}$ Colección de Historiadores de Chile y de Documento relativos a la Historia Nacional (Santiago de Chile, Imprenta Elzeviriana, 1901), XXIV, p. 303. 
como una de ellas que: "En lugar del doctor [Pedro de] Nava, que por sus enfermedades no puede servir como era menester, se pusiese otro de los que de yuso se nombrarán y a él se le diese por lo que ha servido el salario en su casa" ${ }^{47}$.

En tiempos de Felipe II, en el uso del Sacro y Supremo Consejo de Aragón, por ejemplo, en consulta de 4 de febrero de 1589, respecto del doctor Tomás Escapolar, juez de Corte de la audiencia de Cerdeña, se leía que: "Ha parecido que por lo que este supp. to ha servido muchos años y bien este oficio de Juez de Corte, y quedar con mucha pobreza y necesidad, y por aver perdido la vista sirviendo, siendo V. Mag. ${ }^{d}$ servido, se le podría hacer mrd que gozasse del salario del dho oficio en su casa, q' son trezientas libras catalanas al año, durante su vida, y de quinientas libras catalanas por una vez.para los gastos que se le ofrecen en volverse con su casa e hijos a Barcelona, y q' todo se le consigne sobre la Procu. ${ }^{\text {on }}$ real de Mallorca" 48 .

Su calificación de merced era la habitual en el lenguaje de las secretarías y en el de los mismos sujetos que servían un oficio. Así, cuando a don Antonio de Salazar, oidor que era de la Real Audiencia de Panamá, se le concedió el salario en su casa, sus colegas de la audiencia escribían al rey que no había llegado a gozar de esta merced debido a su muerte: “Murio sin gozar la m[e]r[ced] q' V. Mag. ${ }^{d}$ le avia fecho de darle el salario en su casa" ". Este carácter de merced, en cuanto que justa retribución de méritos y servicios, se destacaba cuando en alguna ocasión se la calificaba como recompensa. Así, por ejemplo, el Sacro y Supremo Consejo de Aragón, en consulta de 13 de agosto de 1589: "Pidiose información al Virrey de V alencia de personas para la plaça de Juez de Corte del rey. ${ }^{\circ}$ de Cerdeña que vaca por el impedimento de vista del doctor Thomas Escapolat a quien por esta causa V. M. ' ha dado recompensa para que se vaya a su casa $[\ldots]^{\prime, 50}$.

Su directa vinculación con el sustento del oficial sin que tuviera necesidad de servir para lograrlo, resultaba muy clara, por ejemplo, en la consulta del Consejo de Indias, de 16 de noviembre de 1580, en la que estimaba la petición de un contador real de Yucatán: "Fran." Pacheco Contador de real hazienda de la provincia de yucatan ha supplicado a V. M. que atento a que ha mas de veinte y siete años que sirve a $V$. M. en aquella tierra y los veinte dellos en el dicho off. ${ }^{y}$ que agora está tullido de pies y de manos y no puede escribir ni firmar, si no con mucho trabajo, se le haga merced de darle licencia para que pueda renunciar aquel officio en persona suffiçiente, o se le dé el sala. en su casa por los días de su vida con que pueda sustentarse [...] paresçe al Consejo que siendo V. M. ser.do se le podía hazer merçed de mandarle dar por los días de su vida la mitad del salario, que son cient mil mrs, con que se pueda sustentar en su casa [...]"51.

El uso de las expresiones "grata licencia" y "gozar del salario en su casa" comenzó a decaer, con claridad, desde principios del siglo XVII. A medida que avanzó esta centuria fue cada vez más raro usar de ellas, y prácticamente desaparecieron

\footnotetext{
${ }^{47}$ En Beltrán de Heredia, Vicente, Cartulario de la Universidad de Salamanca (1218-1600) (Salamanca, Ediciones de la Universidad de Salamanca, 1970), II, p. 506.

${ }^{48}$ AcA. Consejo de Aragón, leg. 1.053, n. 2.

${ }^{49}$ Agr. Panamá, 14, r. 13, n. 88, “Los oidores Villanueva Zapata y Arias Ugarte al rey”, Panamá,

${ }^{50}$ AcA. Consejo de Aragón, leg. 1.053, n. 6.

${ }^{51}$ A Gi. Indiferente General, 739, n. 285.
} 27-X-1597. 
en el curso de su segunda mitad, al hilo de la fuerza substitutiva que cobró la voz jubilación.

\section{LA “EXONERACIÓN” DEL OFICIO: LA “JUBILACIÓN”}

La voz jubilación se hallaba en uso durante el siglo XVI, con una significación genérica, de gozo, tomada del campo de la teología en el que, formada de la latina iubilatio y aplicada a ángeles y particularmente a la virgen María ${ }^{52}$, era entendida como un muy particular e inexplicable gozo y contento, ligado a la contemplación de Dios $^{53}$, causado en él y manifestación del consuelo que prodigaba a sus hijos ${ }^{54}$.

De aquella significación se tomó, por especie de figura, la del verbo jubilar y su participio pasado jubilado, para referir éste a quien era absuelto de su trabajo, por el alivio y gozo que ello conllevaba. Así ya lo registraba Nebrija en su Dictionarium: "Jubilado suelto de trabajo, emeritus, a, um. Jubilar suelto ser assi" 55 . Tempranamente fue admitido en el lenguaje de los oficios universitarios, en especial, en relación con las cátedras y, por ejemplo, en los Estatutos universitarios, al menos desde el siglo XVI, se recurría a las voces jubilar, jubilación y jubilado, con la significación que a principios del siglo XVII le daba Covarrubias en su Tesoro: "Ivbilar, es absolver a uno del trabajo, en el ministerio que por muchos años ha servido; como se haze en Salamanca, y en las demás vniversidades, quando algún Doctor, o Maestro ha leydo catreda de propiedad veinte años, o mas, o menos como es costumbre: y tambien en las yglesias Catredales jubilan los prebendados a quarenta años de residencia, o mas, o menos" 56 .

La voz jubilación, con tal significación de liberación del ejercicio de un oficio real, comenzó a utilizarse en tiempos de Felipe II, de guisa que, desde las últimas décadas del siglo XVI, ocasionalmente se la leía en memoriales de oficiales, en papeles de las secretarías de los Consejos, y en algunas reales disposiciones, y que ya en el siglo siguiente fuera habitual en los juristas y otros escritores. Así, por ejemplo, Bermúdez advertía que los modernos llamaban jubilación a aquello que los antiguos habían llamado vacación: "V acaciones llamaron los antiguos, al punto, y término de las ocupaciones, o cuydados públicos, al ocio de los negocios, y quietud dellos, a la tarea de cada dia en paz. o en guerra, dize el sagrado Texto, y el derecho, y so desta benignidad con los envejecidos en el Tribunal, o en la campaña, a todos concede indulgencia plenaria para

${ }^{52}$ Bustis, Bernardinus de, Mariale de singulis festivitatibus beate virginis per modum sermonum tractans (Hagenaw, in Officina Henrici Gran, 1506), Pars XI, Incipit, sin foliar: "In quod tractatur de gloriose virginis mariae assumptione et particular ac proprio nomine Jubilatio angelica nuncupat".

${ }^{53}$ Granada, Luis de, Guia de pecadores (Salamanca, por los herederos de Mathias Gast, 1580), fol. 77: "Mas el sancto rey (que de todo esto sabia mucho) no dize sino que aquel es bienaventurado, que sabe por experiencia que cosa sea alegrarse y gozarse en Dios, no con qualquier manera de gozo, sino con aquel que merece nombre de jubilación: el qual (como dice sant Grego.) es un gozo del spiritu tan grande, que ni se puede explicar con palabras, ni dexa de manifestar con muestras y obras exteriores".

${ }^{54}$ Ibíd.: "¿Pues si el mismo Dios es el autor deste gozo, y jubilación, que tal será el gozo causado por Dios? Porque cierto es que assi como generalmente hablando, el castigo de Dios es conforme al mismo Dios, assi también el consuelo de Dios suele ser conforme a ép'.

${ }^{55}$ Nebrija, Elio Antonio de, Grammatici dictionum hispaniaru $[\mathrm{m}]$ in latinum (Salamanca, in domo Ioannis Varele salmanticensis, 1516), fol. 45v.

${ }^{56}$ Covarrubias Orozco, Sebastián de, cit. (n. 6), fol. 492. 
descansar en su casa [...] Iubilo la llaman los modernos, y es Iubileo de peligro de muerte" ${ }^{\text {". }}$. Por esta misma época el doble uso de vacación y j u b i l a c i ó n se leía en un Memorial de Solórzano y Pereyra, en el que se destacaba su núcleo, centrado en la exoneración del uso y ejercicio, y el consiguiente descanso a que se había hecho merecedor el oficial: "Los vacantes, o Iubilados, que aviendo tenido exercicio, por vejez, o por otro accidente, merecieron del Principe, que exonerados del, pudiessen vacar a su sola quietud i descanso" 58 .

Aunque en un primer momento no se advierte que el uso de la voz jubilación se ciñera a un significado preciso y técnico, sí implicaba la idea de entender a la jubilación como una merced real, y con él se presentaba con cierta frecuencia en el espacio de los oficios de Indias.

En real cédula fechada en Elvas el 3 de enero de 1581, se refería que Sebastián Vázquez, relator de la Real Audiencia de Méjico, había suplicado al rey: "Que teniendo consideración a los muchos años que ba servido y que está muy viejo y enfermo y con necesidad le hiciésemos mrd de mandarle jubilar del dho oficio de Relator y q' en esa Real Caja se le diesen quinientos pesos de minas en cada un año por los días de su vida y de la de su muger "59. Don Felipe II sólo tuvo por bien recomendar sus méritos al virrey, de modo, que en lo decisivo de la citada real cédula no hay referencia alguna a la jubilación. De ese mismo año, y fechada en Lisboa el 28 de octubre de 1581, era una real cédula en la que se recibía la expresión estar jubilado, para tratar a Antonio Bermúdez, contador de la real hacienda de Cartagena: "Aviendo servido muchos años por vuestra mucha edad y continuas enfermedades os hicimos merced de os jubilar del uso del dicho oficio, y que gozassedes del salario que con el teniades [...] y no aveis suplicado [...] os hiziessemos merced de declarar y mandar que sin embargo de estar jubilado del dicho oficio tuviessedes en las Yglesias y demás partes donde concurriessedes con los nuestros oficiales de nuestra real hazienda de la dicha provincia el mismo lugar que teniades antes de ser jubilado, o como la nuestra merced fuese" ${ }^{\prime 60}$.

La jubilación en este tiempo inicial de su uso comenzaba a definirse como una cierta merced real, en cuanto que remuneraba los méritos y servicios de un oficial real anciano y achacoso, merced que consistía en exonerarle del uso y ejercicio de su oficio, pero con el goce de su salario. Esta significación la acercaba estrechamente a la expresión "gozar del salario en su casa", de ahí que no resulte extraño que se la empleara junto a ella. Se las veía ligadas, por ejemplo, en la carta que dos oidores de Panamá dirigían a Felipe II en febrero de 1598: "Suplicamos humildemente a V. Mag. ${ }^{d}$ en remuneración de los servi. ${ }^{\text {s }}$ de nros padres y de los nuestros, y satisfacion del honor, que corre riesgo por vernos como sepultados en olvido, los hombres graves que saben la

\footnotetext{
${ }^{57}$ Bermúdez de Pedraza, Francisco, Hospital Real de la Corte (Madrid, 1645), fol. 91r.

${ }^{58}$ Solórzano y Pereira, Juan de, Memorial o Discurso informativo iuridico, historico, politico. De los Derechos, Honores, Preeminencias, $i$ otras cosas que se deben dar, i guardar a los Consejeros honorarios, $i$ iubilados. I en particular si se les debe dar la Pitança que llaman de la Candelaria (Madrid, Por Francisco Martínez, 1642), n. 213, fol. 97.

${ }^{59}$ Agr. Méjico, 1.091, 1. 9, fol. 245r.

${ }^{60}$ EnCINAS, Diego de, Libro tercero de provisiones, cedvlas, capitvlos de ordenanças, instruciones, y cartas, libradas y despachadas [...] tocantes al buen govierno de las Yndias, y administración de la justicia en ellas (Madrid, Imprenta Real, 1596), fol. 287.
} 
pureza de nros servi. ${ }^{\text {s }}$ y por nuestros papeles que ya se abran visto en el Real consejo se nos haga mrd - al doctor diego de villanueva çapata, por su edad y enfermedades del salario en su casa jubilandole" ${ }^{\prime \prime}$. Dos años más tarde, el Consejo de Indias en consulta de 7 de abril de 1600, proponía a Felipe III que, respecto de las súplicas del oidor Alonso Maldonado de Torres: "Ha paresçido q' por estar viejo y enfermo, siendo V. M. ' servido le podría jubilar haziendole mrd del salario que tiene con su plaça en su casa"62.

En el curso del siglo XVII la voz 'jubilación' se generalizó en el lenguaje de las secretarías de los Consejos, en los reales despachos, en el uso de los mismos oficiales reales, y en el de los juristas de los distintos reinos de la monarquía. Esta generalización estuvo acompañada de dos notas singularmente relevantes, en relación con su significación, a saber: el progresivo abandono de la expresión "gozar del salario en su casa", y la paulatina definición de la jubilación como una palabra con un significado preciso y delimitado respecto de los oficios reales.

La voz jubilación se consolidó con la significación de exoneración del uso y ejercicio del oficio, acompañada de la merced del goce de salario, en el todo o en parte y, en ocasiones, junto a la conservación de los honores y preeminencias del oficio. Este genérico modo de entenderla dio pie a que se diferenciaran dos especies de ella, en atención a las causas que podían haber movido al príncipe a concederla. Una era, la que asumía la tradición de la "grata licencia" y del "goce del salario en su casa", es decir, la consistente en una merced, que se presentaba como remuneración o premio de los dilatados servicios de un oficial, cuya edad o achaques le impedían servir apropiadamente su oficio. Otra era la que se acordaba por el príncipe como demostración del desagrado real por determinadas conductas del oficial, y en este caso la jubilación se alzaba como una manifestación de la desgracia o disfavor real

En la práctica y estilo institucional de la segunda mitad del siglo XVII se consolidaron estas dos maneras de jubilación, y se explicaban desde la perspectiva de quién instaba por ella. Así, el Sacro y Supremo Consejo de Aragón, cuando en 1669 hubo de cumplir con un real decreto que le ordenaba que mandara formar dos despachos de jubilación de oidores de la Real Audiencia de Cerdeña, con los nombres en blanco, para que el rey usara de ellos según lo tuviera por conveniente, se pidió a su secretario que informara sobre el modo y forma en que se daban tales despachos. En el borrador de la noticia que dio al Consejo sobre este punto, representó que: "Hay dos maneras de jubilaciones""3. A la una la llamaba "a instancia del ministro" y a la otra "de oficio".

\section{La jubilación como merced remuneratoria ("a instancias del ministro")}

La primera especie de jubilación se presentaba, en el siglo XVII, como una categoría en la que se asumió el contenido de la tradición previa de la "grata licencia" y del "goce del salario en su casa” y, por ende, con un esencial carácter de merced remuneratoria de méritos y buenos servicios.

\footnotetext{
${ }^{61}$ Agr. Panamá, 14, r. 14, n. 94, "D. Diego de Villanueva Zapata y D. Francisco Valverde de Mercado al rey”, Panamá, 18-II-1598.

${ }^{62}$ Agi. Panamá, 1, n. 151.

${ }^{63}$ AcA. Consejo de Aragón, leg. 1.054, n. 130.
} 
A tal jubilación el Sacro y Supremo Consejo de Aragón la llamaba “a instancias del ministro" y decía de ella: "La otra manera de Jubilacion es a instancia del ministro que desea la Jubilacion y la pide con mem.' con motivos que representa para ello, y si Su Mag. la concede acostumbra reservarles los honores y salario entero que gozava con la ocupación que tenia" "64. En este caso la jubilación constituía una merced real, que retribuía los méritos y servicios del jubilado, al que, por hallarse impedido de servir su oficio adecuadamente, se le exoneraba de la obligación de servirlo y se le daba el goce de su salario, de por vida y, con frecuencia, se le conservaban sus honras y preeminencias. Aquí la voz jubilación se empleaba como equivalente de la más antigua expresión "gozar del salario en su casa", cuyos resabios aún se conservaban en los primeros decenios del siglo XVII.

El carácter de merced, sus causas en la edad y achaques, y el uso de una terminología tradicional, unida a la más novedosa de jubilación, se apreciaba en una consulta del Consejo de Indias, de 7 de abril de 1600, en la que presentaba al monarca la pretensión de don Alonso Maldonado de Torres, de que se le jubilara de su oficio de oidor de Panamá: "Porparte del licenciado Alonso de la Torre oydor mas antiguo de la audiencia de Panama se a representado q' ha mas de treynta años q' sirve en las audiencias de aquellas partes. Los diezy siete dellos en la que esta al presente, sin que se le haya becho mrd alguna en gratificacion dellos, y que al presente se halla tan viejo y corto de vista y enfermo que no lo puede continuar como quisiera [...] Y en remuneracion de los dhos servicios, por no poder continuarlos, se la haga V.M. ${ }^{d}$ de jubilarlo con el salario que tienen los oydores de la audiencia de Lima, donde piensa acavar lo poco que le queda de vida" ${ }^{\prime 65}$. La real resolución también daba cuenta del uso de voces más antiguas y más novedosas: "Jubilesse y bastara darle el sueldo de su plaza en su cassa" ".

El uso conjunto de la expresión "salario en su casa” y "jubilación" también se mantenía en la real cédula que, fechada en Ventosilla el 17 de octubre de 1620, se dirigía a los oficiales reales de la ciudad de Méjico para comunicarles la jubilación del oidor don Antonio Maldonado: "Oficiales de mi Real Haz: de la ciudad de mexico de la nueva spaña. Teniendo consideración a los muchos años que el liçen. Ao Antonio Maldonado mi oydor que al press.te es de mi Real aud. ${ }^{a}$ de essa ciudad ha servido al Rey mi señor, que aya gloria, y a mi, y a que por haverle cargado sus enfermedades se halla impedido para podello continuar, he tenido por bien de jubilarle y hacerle $m[e] r[c e] d$, como por la press. ${ }^{\text {te }}$ se la hago de los ochocientos mil mrs de salario que tiene con la dha plaça, para que durante su vida goçe de ellos en su casa, sin oblig. on de servir, y assi os mando que desde el dia de la fecha desta mi çedula en adelante le acudáis estando en su casa o donde quissiere o por bien tuviere con los dos ochocientos mil mrs en cada un año [...]" $]^{\text {67 }}$.

$\mathrm{Al}$ avanzar el siglo XVII la voz jubilación tendió a desplazar a las expresiones anteriores, y asumía en plenitud el carácter de merced real, consistente en la exoneración del uso y ejercicio del oficio, causada en los achaques u otros accidentes del oficial, en cuanto que retribución a sus méritos y buenos servicios, y comprensiva del goce del salario íntegro y de los honores del oficio. Su carácter

\footnotetext{
${ }^{64}$ Ibíd.

${ }^{65}$ Agi. Panamá, 1, n. 151.

${ }^{66}$ Ibíd.

${ }^{67}$ Agr. México, 1.093, 1. 15, fol. 257r-257v.
} 
de merced y, en cuanto que tal, su vinculación con la justicia retributiva, hizo que tempranamente algunos juristas, como Solórzano y Pereira, destacaran que la jubilación se presentaba como una merced d e b i d a por el príncipe: "Estas Iubilaciones son debidas, i mui forçosas en los Magistrados perpetuos, que llegan a envegecer, o ballarse impedidos por otro accidente en el Real Servicio, $i$ que aliis praemiis \& bonorifica quiete donandi sunt ${ }^{\prime 68}$. De esa misma naturaleza premial de esta especie de jubilación, se seguía la conservación de los honores y preeminencias del antiguo oficio, pues su mantenimiento en el jubilado, era señal de la retribución de sus méritos y buenos servicios y, por lo mismo, eran merced perpetua: "Estos tales, assi por derecho comun $i$ del Reino, como por practica i observancia inconcussa, conservan siempre sus lugares, precedencias, i preeminencias, en honra i premio de la dignidad que tuvieron, $i$ administraron, cuyas reliquias o privilegios nunca se pierden una vez adquiridos" ${ }^{69}$.

La práctica en la Monarquía hispana, consolidó, así, durante el siglo XVII una primera especie de jubilación que: a) era merced real, b) causada en los achaques o accidentes del oficial, c) cuyo contenido básico era la exoneración del uso y ejercicio del oficio, d) extensiva a la conservación de su salario íntegro, propinas y demás emolumentos, y a los honores y preeminencias que le eran propios, y e) ordinariamente solicitada por el mismo oficial.

Esa concepción no era más que la generalización de la práctica y estilo observados en la Monarquía, y de los que daban buena cuenta las consultas y despachos de las jubilaciones desde mediados del siglo XVII. Así, por ejemplo, podía leerse en la real cédula fechada en Zaragoza el 30 de julio de 1646, que hacía merced de jubilar a don Jerónimo Funes y Muñoz, del oficio de conservador general del patrimonio de Nápoles, Sicilia y Milán ${ }^{70}$. En el siglo XVIII fue mucho más corriente que se recurriera a la sola voz jubilación, en estos casos en los que con ella se remuneraban los servicios de un antiguo oficial que, por su edad o achaques,

${ }^{68}$ Solórzano y Pereira, Juan de, cit. (n. 58), n. 221, fol. 101.

${ }^{69}$ Ibíd., n. 213, fol. 97.

${ }^{70}$ Ags. Secretarías Provinciales, libro 636, fol. 107r-108r: "Por quanto haviendome supplicado el Consegero Don Geronimo Funes y Muñoz cavallero de la Orden de Santiago Gentilhombre de mi boca de mi Consejo de Italia y Conservador gral de mi R.' patrimonio de los Reynos de Nap.' y Sicilia y estado de Milan fuesse servido de honrrarle concediendole la jubilacion de la Plaça de Conservador gral, attento que por su mucha edad siente hallarse impossibilitado de poder continuar mi R.' servicio con la atencion y vigilancia que hasta aqui lo ha hecho. Por tanto atendiendo consideracion a sus muchos y partes servicios y que los ha continuado por espacio de 45 años continuos en la dha Plaça de Conservador gral siendo los nueve ultimos Consejero de capa y Espada en el dho mi Consejo de Italia donde ha procedido con toda rectitud entereza y zelo grande de mi servicio mirando con particular atencion las cosas pertenecientes a mi R.' Hacienda y patrimonio [...] he tenido por bien y por consuelo suyo de concederle la jubilacion que pide, como por la presente se la concedo, y en demostracion de quan agradables me han sido sus servicios y que en todo tiempo conste dello y que de su persona y del amor y fineza con que los ha continuado tengo particular estimacion quiero y es mi voluntad que con la jubilacion de la dha Plaça de Conservador goce de todos los honores preeminencias precedencias prerogativas y auctoridades della según y como y en la misma forma y manera que las tenia y gozava podia y devia gozar antes de la jubilacion y que mientras el dho D." Geronimo viviere el dho Consejo tenga su persona y servicios en la buena qu. ${ }^{\text {ta }} y$ estimacion que es justo Y mando que el salario y demas emolumentos y propinas de la dha plaça de conservador que importaban 28.367 Reales en plata doble cada año se le paguen en moneda de vellon en la nomina de mis Consejos por el Pagador delllos con tal precision y puntualidad que no le haga falta para su sustento y que estos le corran y se le hagan buenos desde primero de enero deste presente año de 646 en adelante mientras viviere". 
no podía continuar en el desempeño de su oficio y, al efecto, se le exoneraba del uso y ejercicio, y se le conservaban el salario y honores. Así, por ejemplo, después de que Francisco Suárez de Deza, regente de la Audiencia y Chancillería Real de Granada, solicitara su jubilación, fundado en su edad y achaques, por real decreto fechado en Aranjuez el 26 de marzo de 1805 le fue concedida: "En atención a la avanzada edad, achaques y buenos servicios, de D. "Francisco Duarez de Deza y Yebra, Regente de la Chancillería de Granada, vengo en jubilarle, conservándole sus sueldos y honores" ${ }^{\prime 71}$. Similares términos se usaban en la real orden, fechada en Madrid el 3 de junio de 1804, por la que se comunicaba la jubilación de don Julián de Ocariz, oidor del Consejo Real de Navarra: "En atención a la abanzada hedady achaques y al merito y servicios que V.m ha contraido en su empleo de Ministro de ese Consejo, se ha servido el Rey (Dios le gu.e) jubilarle con todos sus honores, sueldos y emolumentos que goza" ${ }^{\text {"72. }}$.

\section{La jubilación como medida de buen servicio ("de oficio")}

La otra especie de jubilación, llamada de oficio, carecía del carácter de merced, y se presentaba como una decisión del príncipe, dirigida a exonerar del uso y ejercicio del oficio a un oficial que, por justas causas, no convenía que continuara en él y que, en atención a las razones que movían a exonerarle, podía extenderse a la conservación de una parte de su salario, y a los honores y preeminencias del oficio.

A ella se refería el Consejo de Aragón, en su citada consulta de 1669, y la describía de esta manera: "La primera es la que su Mag." manda hacer de oficio, y entonces declara la canty [da]d de salario que se ha de reservar al Jubilado, y se le da despacho en toda forma, motivando que él lo ha pedido por algunos motivos, o, de estar viejo, o, con algunos achaques que le impiden el exercicio de su oficio, para que el Ministro quede con los honores del cargo que ocupava. Y de ordinario su Mag. "les manda reservar con los honores la mitad del salario"73.

Que, en este caso, la decisión del monarca solía hallarse en la conducta del oficial, que daba pie a la decisión de jubilarse quedaba claro cuando, por ejemplo, recibido el despacho de su jubilación por el doctor Domingo Brunengo, oidor de la Real Audiencia de Cerdeña, la representó desde Caller el 8 de octubre de 1669: "Despues de haver, por espacio de veinte y quatro años ocupado plaça de Ministro en este Reyno y en los diezy ocho últimos la de Oydor de la Real Audiencia Civil, ba sido V. Mag.d servido de Jubilarme sin haverlo yo supplicado, que me ha dado occasion de sospechar que algún émulo fingiendo incapacidad en mi persona, faltas en las obligaciones de mi oficio, e imposibilidad en continuarle, la bará, por sus segundas intençiones, procurado, entendiendo con esto poner nota y sombra a mi lealtad y entereza [...]"74.

El desconsuelo que le produjo lo exponía el Consejo de Aragón, al consultar al monarca el 15 de septiembre de 1670, lo que resultaba del Memorial de Brunengo y de las causas que habían motivado su jubilación: "El desconsuelo con que se balla de que le hayan Jubilado en la Plaza de Oydor de la Aud. ${ }^{a}$ de Cerdeña [...] En la carta refiere que después de haver por espacio de veinte y quatro años ocupado Plaça de Ministro en aquel Reyno, y en los dieciocho últimos la de Oydor de la Real Audiencia Civil, ba sido V. M. ${ }^{d}$

\footnotetext{
${ }^{71}$ Ahn. Consejos, leg. 13.526, s/n.

${ }^{72}$ Argn. Comptos, Mercedes Reales, libro 42-2, fol. 234r.

${ }^{73}$ Aca. Consejo de Aragón, leg. 1.054, n. 130.

${ }^{74}$ Ibíd., n. 139.
} 
servida de Jubilarle, sin haverlo él supplicado, representando, que habrá sido efecto de alguna emulación, a que procura satisfacer [...] Después [El Consejo] ha tenido noticias por lo que el Virrey ha escrito de los motivos, que representó a $V . M .{ }^{d}$, y no sólo han sido bastantes para esta demostración, sobre sus muchos años, sino que merecian mayor castigo, pues es grave culpa en un Ministro faltar el respeto del que representa a V.M. ${ }^{d}$, como lo bizo D. Domingo votando en un negocio en la Audiencia en presencia del Virrey"75.

En definitiva, este otro modo de jubilación, se decidía por el rey motu proprio, fundado en conveniencias del servicio real, de guisa que en este caso no se presentaba como una merced, es decir, no remuneraba méritos, ni largos servicios, sino que ordinariamente obedecía a la necesidad de que el oficial cesara en el servicio, por causas que volvían justificable esta decisión, sin que fueran bastantes para dar pie a su privación o a otras demostraciones. Con todo, en este caso mostraba, igualmente, un cierto cariz de misericordia, pues el rey coloreaba con la jubilación una muestra de su disfavor, y de la desgracia en la que había incurrido el ministro jubilado.

\section{ConClusión}

El examen del oficio, contextualizado por la cultura jurisdiccional en la que se configuró, da cuenta de la centralidad que asumió su originaria vinculación con la noción de deber y, por esta vía con la de carga (onus).

Uno de los campos en los que, con claridad, se proyectó esa relación entre oficio y carga fue el del uso y ejercicio del oficio, pues se lo entendía como el cumplimiento de la carga impuesta por el propio oficio.

Esa misma conexión es la que se hallaba tras la posibilidad de exoneración del uso y ejercicio, pues ella no era más que la liberación de la carga que él implicaba para el oficial. Uno de los espacios en los que se proyectó la exoneración fue aquel que dio lugar a la consolidación de la categoría de la jubilación.

La jubilación, en cuanto que categoría y que voz técnica, es consecuencia de un determinado curso histórico, y representa un cierto momento y estadio del oficio en el amplio espacio de la cultura del derecho común. Incardinada en la noción de deber y carga, su desarrollo se ligó a la idea de merced y, por esta vía, a la de los méritos y servicios. Pero también se convirtió en un dispositivo para procurar el más cumplido ejercicio del deber del príncipe de mantener a su pueblo en justicia, pues en otro de sus campos, con ella se apartaba a oficial que no convenía que continuaran en el uso y ejercicio de oficios reales.

La ligera revisión de ese curso histórico permite destacar, además, el papel que jugaron las expresiones técnicas con las que se definió el lenguaje de uno de los supuestos de cese en el uso y ejercicio del oficio.

${ }^{75}$ Ibíd., n. 134. 
BARRIENTOS Grandon, Javier, El oficio y su proyección en el lenguaje de las residencias: "bueno, recto y limpio juez”, en Andújar Castillo, F. y Ponce Leiva, P. (coord.), Debates sobre la corrupción en el Mundo Ibérico, siglos XVI-XVII (Alicante, Biblioteca Virtual Miguel de Cervantes, 2108), pp. 83-102.

-La Cámara de Castilla: "Méritos", "servicios" y "suficiencia" en la provisión de oficios del Consejo de Indias en tiempos de Felipe II (1588-1598), en Boletin de la Academia Chilena de la Historia, 126 (2017), pp. 149-225.

Beltrán de Heredia, Vicente, Cartulario de la Universidad de Salamanca (1218-1600) (Salamanca, Ediciones de la Universidad de Salamanca, 1970), II.

Bermúdez de Pedraza, Francisco, Hospital Real de la Corte (Madrid, 1645).

Bustis, Bernardinus de, Mariale de singulis festivitatibus beate virginis per modum sermonum tractans (Hagenaw, in Officina Henrici Gran, 1506).

Calepino, Ambrogio, Dictionarium linguae latinae (Basileae, ex officina Hieronymi Curionis, 1566).

Cenedo, Pedro, Practicae quaestiones canonicae, et civiles, tam utriusque iuris, quam sacrarum Literarum studiosis utilissimae (Zaragoza, apud Ioannem a Lanaja \& Quartanet, 1614).

Cicero, M. Tullius, De finibus bonorum et malorum libri $V$ (Lipsiae, sumptibus Augusti Lehnhold, Lipsiae, 1831).

Cicero, M. Tullius, Epistolae ad Atticum (Ingolstadii, ex Typographia Adami Sartorii, 1615).

Colección de Historiadores de Chile y de Documento relativos a la Historia Nacional (Santiago de Chile, Imprenta Elzeviriana, 1901), XXIV.

Covarrubias y Orozco, Sebastián de, Tesoro de la lengua castellana o española (Madrid, por Luis Sánchez, 1611).

ENCINAS, Diego de, Libro tercero de provisiones, cedvlas, capitvlos de ordenanças, instruciones, y cartas, libradas y despachadas [...] tocantes al buen govierno de las Yndias, y administración de la justicia en ellas (Madrid, Imprenta Real, 1596).

Diccionario de la lengua castellana, en que se explica el verdadero sentido de las voces (Madrid, Imprenta de la Real Academia Española, por los Herederos de Francisco del Hierro, 1737), V.

Granad, Luis de, Guia de pecadores (Salamanca, por los herederos de Mathias Gast, 1580).

Nebrija, Elio Antonio de, Grammatici dictionum hispaniaru $[m]$ in latinum (Salamanca, in domo Ioannis Varele salmanticensis, 1516).

NeBRIJA, Antonio de, Dictionarium latinohispanicum, et viceversa hispanicolatinum (Antuerpia, in Aedibus Ioannis Steelsii, 1560).

Prateius, Pardulfus, Lexicon juris Civilis et Canonici, sive potius Thesaurus, de verborum, quae ad Ius pertinent, significatione, P. Prateio ex variis Collectore (Lugduni, apud Guliel. Rovillium, 1567).

Quevedo y Villegas, Francisco de, Política de Dios i Govierno de Christo; sacada de la Sagrada Escritura para acierto del Rey i Reyno en sus acciones (Madrid, a expensas de Pedro Coello, 1655).

Rocco, Francisco, De officiis, eorumque regimine opus decisionibus supremorum magistratuum illustratum (Neapoli, ex Regia Typographia Aegidii Longhi, 1669).

SÁncHEZ, Juan Josef, Nobleza, privilegios y prerrogativas del oficio público de escribano (Valencia, Imprenta de los Hermanos de Orga, 1797), II. 
Santa María, Juan de, Tratado de republica y policia christiana. Para reyes y principes: y para los que en el gobierno tienen sus vezes (Barcelona, por Sebastian de Cormellas, 1618).

Scoт, Alexander, Vocabularium iuris utriusque (Lugduni, apud Symphorianum Beraudum, 1572).

Solórzano y Pereira, Juan de, Memorial o Discurso informativo iuridico, historico, politico. De los Derechos, Honores, Preeminencias, i otras cosas que se deben dar, i guardar a los Consejeros honorarios, i iubilados. I en particular si se les debe dar la Pitança que llaman de la Candelaria (Madrid, Por Francisco Martínez, 1642).

Zurita, Jerónimo, Historia del Rey don Hernando el Catholico. De las empresas, y ligas de Italia, V (Zaragoza, por Lorenzo de Robles, 1610). 